\title{
PATTERNS OF SYNAPTIC INPUT TO LAYER 4 OF CAT STRIATE CORTEX $^{1}$
}

\author{
BARBARA A. MCGUIRE, ${ }^{2}$ JEAN-PIERRE HORNUNG, ${ }^{3}$ CHARLES D. GILBERT, AND \\ TORSTEN N. WIESEL
}

The Rockefeller University, New York, New York 10021

Received January 23, 1984; Revised May 22, 1984; Accepted June 22, 1984

\begin{abstract}
Although cells in layer 4 of cat striate cortex represent the first stage in the cortical processing of visual information, they have considerably more complicated receptive field properties than the afferents to the layer from the lateral geniculate nucleus. In considering how these properties are generated, we have focused on the intrinsic cortical circuitry, and particularly on the projection to layer 4 from layer 6 . Layer 6 pyramidal cells were injected with horseradish peroxidase and examined at the light and electron microscopic level. The labeled axon terminals were found to form asymmetric synapses and to show a strong preference for contacting dendritic shafts. Serial reconstruction of dendrites postsynaptic to labeled layer 6 cell axon terminals showed that a large proportion of the postsynaptic dendrites belonged to smooth and sparsely spiny stellate cells, suggesting a selective innervation of these cell types. In contrast, the geniculate projection to layer 4 made synapses primarily with dendritic spines and, as a result, the large majority of terminals ended on spiny cells. Since smooth and sparsely spiny stellate cells are thought to mediate inhibition within the cortex, we suggest that one effect of the layer 6 to layer 4 projection could be to contribute to inhibitory features of the receptive fields of layer 4 cells.
\end{abstract}

Layer 4 is the primary target of afferents to the cat striate cortex from the lateral geniculate nucleus (LGN) and, as such, represents a first stage in the cortical processing of visual information coming from the periphery. Even so, cells in layer 4 exhibit a rich variety of receptive field properties that are quite distinct from the properties of the geniculate input. Cells in this layer are oriented, binocular, selective for direction of movement and frequently end inhibited, where the geniculate afferents are monocular and, to a first approximation, circularly symmetric. Very little is known about the mechanisms responsible for this transformation. Some of these features could be produced by convergence of geniculate input (Hubel and Wiesel, 1962) or by inhibitory interactions within the layer (Sillito, 1977; Sillito and Versiani, 1977; Sillito et al., 1980). Another source of possible influence is the very substantial projection from layer 6 to layer 4 . This pathway constitutes one of the major components in the intracortical circuit, as demonstrated by Golgi studies in the cat and monkey (Lund and Boothe,

\footnotetext{
${ }^{1}$ This work was supported by National Institutes of Health Grants EY 05253, EY 07042, EY 04782, and NS16189. J. -P. H. was supported by a grant from the Fogarty. International Center (National Institutes of Health) and by the Swiss National Foundation. We thank Adrienne Lynch and John Kanki for their technical assistance, James Hamilton and Joyce Powzyk for help with the illustrations, Eric Hubel for photographic work, and Dr. Giuseppina Raviola for the use of an electron microscope.

${ }^{2}$ To whom correspondence should be addressed.

${ }^{3}$ Present address: Institute of Anatomy, University of Lausanne, Rue du Bugnon 9, 1011 Lausanne, Switzerland.
}

1975; Lund et al., 1979) and by intracellular horseradish peroxidase (HRP) injection studies in the cat (Gilbert and Wiesel, $1979,1981)$. We know from high affinity uptake of the acidic amino acid transmitters, aspartate and glutamate, that the cells participating in the layer 6 to layer 4 projection are likely to be excitatory (Baughman and Gilbert, 1981). Since the layer 6 cells could contact excitatory or inhibitory interneurons in layer 4 , one is still left with a number of possible ways in which layer 6 cells could influence receptive field properties. As the next step in this analysis, it is therefore necessary to identify the second-order neurons in the pathway. We have attempted to do this in the present study by serial electron microscopic (EM) reconstruction of the processes that are postsynaptic to HRPinjected layer 6 cells.

\section{Materials and Methods}

Layer 6 cells and afferents from the LGN were injected with HRP after their receptive fields had been characterized, using a procedure described previously (Gilbert and Wiesel, 1979). Within $12 \mathrm{hr}$ of the first injection and at least $1 \mathrm{hr}$ after the last, the cat was perfused with a saline rinse followed by a mixture of aldehydes $(500 \mathrm{ml}$ of $1 \%$ paraformaldehyde $/ 1 \%$ glutaraldehyde, then $1000 \mathrm{ml}$ of $1 \%$ paraformaldehyde $/ 2 \%$ glutaraldehyde). The brain was blocked and sections were cut on a Vibratome at $50 \mu \mathrm{m}$ and reacted with diaminobenzidine using cobalt intensification (Adams, 1977). Following the histochemical reaction, the sections were prepared either for light microscopy (see Gilbert and Wiesel, 1979) or for electron microscopy as described here. After $30 \mathrm{~min}$ postfixation in osmium ferrocyanide, these sections were stained en bloc overnight in $1 \%$ uranyl acetate in sodium maleate buffer. Then, while kept flat under filter paper, the sections were dehydrated through a series of ethanols and subsequently embedded flat between Aclar sheets in Epon-Araldite.

The cells were first reconstructed in the standard manner, using a 
microscope equipped with a drawing tube and $\times 40$ oil immersion objective (Gilbert and Weisel, 1979). In the present study two cells were chosen for EM analysis; we selected restricted regions within each cell's axonal field (Figs. 1 and 2) and then trimmed the appropriate blocks to a mesa. Serial ultrathin sections with silver to gold interference colors were cut (500 to 600 sections per series) and mounted onto Formvar-coated slot grids according to the method of Stevens et al. (1980). The sections, stained with uranyl acetate and lead citrate, were examined and photographed with a Philips 400 or JEOL 100-CX electron microscope. We were able to locate the labeled axon collaterals by using a map of cell body, blood vessel, and labeled axon positions taken from the top of the block before thin sectioning.

The identification of the postsynaptic processes was done in two stages. Once a labeled synaptic terminal was found, its postsynaptic profile was identified by characteristic ultrastructural features as either a spine, a dendritic shaft, or a cell body. This identification was made over a number of serial sections, usually more than 10 , in order to discriminate reliably between spines containing spine apparatus and slender dendrites containing small amounts of smooth endoplasmic reticulum. A number of postsynaptic profiles were reconstructed from serial sections. The labeled axons and postsynaptic profiles were followed through consecutive sections and photographed at a magnification of $\times 14,000$ to $\times 30,000$. They were traced onto acetate sheets and reconstructed either manually or using a three dimensional computer reconstruction system (Gilbert and Wiesel, 1983).

$E M$ autoradiography. An injection of 50 to $75 \mu \mathrm{Ci}$ of $\mathrm{D}-\left[2,3-{ }^{3} \mathrm{H}\right]$ aspartic acid (New England Nuclear, specific activity $20 \mathrm{Ci} / \mathrm{mmol}, 1 \mu \mathrm{l}$ over $30 \mathrm{~min}$ ) was made in the LGN of a normal adult cat, to label the layer 6 cells and their axon collaterals in layer 4 (Streit, 1980; Baughman and Gilbert, 1981). 'I'he injection within the LGN, which was placed with the help of physiological recording, was made between layers $\mathrm{A}$ and $\mathrm{A} 1$, about $-8^{\circ}$ elevation and $18^{\circ}$ azimuth. This position was later confirmed autoradiographically, and the injection site was shown to include both layers A and A1. Two days after injection, the animal was perfused as described above. The striate cortex block was sectioned on a Vibratome alternating between $100-\mu \mathrm{m}$ sections for electron microscopy and several $30-\mu \mathrm{m}$ sections for scintillation counts and light autoradiography, using 1- to 6-week exposure for the cortex sections and 1 to 2 weeks for the thalamus sections.

We selected the $100-\mu \mathrm{m}$ sections for osmication and embedding according to the scintillation counts of the adjacent $30-\mu \mathrm{m}$ sections, and we trimmed the plastic-embedded blocks into mesas according to the results of the light microscopic autoradiography. The resulting mesas were semithin sectioned ( 1 to $2 \mu \mathrm{m}$ thick) and processed for light autoradiography, and subsequently serially thin-sectioned (in series of 100 to 200 sections) for EM autoradiography according to the method of Davis et al. (1979). After 5 months exposure, the ultrathin sections were developed in D-19 and photographed at $\times 3300$ with the electron microscope. Labeled synaptic terminals within the middle of layer 4 were identified by the presence of one or several silver grains centered on the terminal. The processes postsynaptic to the labeled terminals were identified as spines, dendritic shafts, or cell bodies by following them over a series of serial EM autoradiograms. To determine whether the terminals containing silver grains were specifically labeled, we compared the distribution of labeled synapses with that of the whole population of synapses in the same region. We chose an area of $20 \times$ $60 \mu \mathrm{m}$, counted every synapse with a postsynaptic density in any one of five serial autoradiograms, and classified the postsynaptic processes in a similar fashion.

\section{Results}

A total of $10 \mathrm{HRP}$-injected layer 6 pyramidal neurons with extensive projections to layer 4 have been reconstructed (see Figs. 1 and 2). Six of these were from normal cats, and four were from monocularly deprived cats. The receptive field properties of the group were mixed: six were complex and four were simple, with both normal and deprived cells in each group. Four (both simple and complex) had long receptive fields which were at least $4^{\circ}$ in one dimension, and six cells had shorter receptive fields. We chose two neurons with complex receptive fields for ultrastructural analysis, one with a long field (neuron 1) and the other with a short field (neuron 2). The location of the axon collaterals chosen for EM analysis is indicated in Figures 1 and 2. Neuron 1 (Fig. 1) had a complex receptive field that was quite long $\left(8^{\circ} \times 4^{\circ}\right)$, a characteristic of many cells in this layer. Although taken from a monocularly deprived cat, it did not appear different in its axonal arbor from layer 6 cells injected in normal animals (see Fig. 5; Gilbert and Wiesel, 1979). Neuron 2 (Fig. 2), from a normal cat, also had a complex receptive field. This field appeared to be small $\left(1.25 \times 1.25^{\circ}\right)$, although we did not do a length-response curve, which is sometimes necessary to determine the full extent of receptive fields in layer 6 (Gilbert, 1977).

At the light microscopic level, the collaterals of layer 6 pyramidal cells in layer 4 appeared quite different from afferents from the LGN. A camera lucida drawing of one of the layer 6 cell collaterals is shown in Figure 3 next to an HRPinjected LGN Y-afferent. The LGN axon was stout, with many synaptic boutons located en passant along the length of the branch. The layer 6 axon, in contrast, was slender and formed most of its boutons at the tips of small side twigs.

At the ultrastructural level the labeled layer 6 terminals varied in the density of their HRP label (Figs. 4 and 5). In the light and medium stained profiles it was possible to determine that the terminals contained round vesicles and formed asymmetric synapses. By tracing the labeled axon collaterals through serial sections, we located a total of 101 synapses from neuron 1 and 50 synapses from neuron 2 . Consistent with the light microscopic appearance, of a sample of 35 labeled and reconstructed synaptic terminals from the second neuron, 33 boutons were located at the end of slender side twigs (Fig. 5) and only 2 synapses were made en passant. Synaptic contacts were only seen at swellings along the axon, and in almost every case ( 150 of 151), a labeled swelling made a single synaptic contact. In contrast, $20 \%$ ( 4 of 21 ) of serially reconstructed terminals from the labeled geniculate Y-afferent (shown in Fig. 3) made multiple contacts with either two or three profiles. The remaining 17 each made a single synapse, for a total of 27 contacts. These results are consistent with those of Winfield and Powell (1983), who found that LGN terminals in layer 4 often make multiple synaptic contacts.

In examining the profiles postsynaptic to the labeled layer 6 cell synapses, we found that the labeled axon terminals contacted the shafts of dendrites (axodendritic contacts) much more frequently than the spines (axospinous contacts). No contacts were seen on cell bodies or axon initial segments. The first neuron made 68 axodendritic and 33 axospinous synapses, and the second neuron made 41 axodendritic and 9 axospinous synapses. Combining the results from the two cells, $72 \%$ of the synapses were with dendritic shafts and $28 \%$ were with spines (Table I). In contrast, previous work has shown that the projection from the LGN has the opposite pattern, with approximately $80 \%$ of geniculate afferents ending on spines, $15 \%$ on dendritic shafts, and 5\% on cell bodies (Garey and Powell, 1971; LeVay and Gilbert, 1976; Winfield and Powell, 1983). In the present study, our preliminary evidence corroborates these earlier results. Of a small sample (27) of HRP-labeled synaptic terminals taken from a single LGN Y-afferent, an overwhelming majority $(93 \%)$ of synapses were made with spines, and the remaining few $(7 \%)$ were made with dendritic shafts. Although the figures have not been normalized to synaptic size, they nonetheless represent a marked difference in the relative distributions of inputs of the two different projections to layer 4 .

Having determined the nature of the synapses generated by the pathway from layer 6 to layer 4, we next attempted to identify the postsynaptic cells. Obviously it is very impractical to do complete serial EM reconstructions of all of the cells contacted by a labeled axon collateral. However, by reconstructing limited portions of the postsynaptic dendrites (from 6 to 50 $\mu \mathrm{m})$ we were able, in many instances, to classify the cells to which they belonged. In so doing we grouped the dendrites into three major classes: smooth, sparsely spiny, and spiny. 


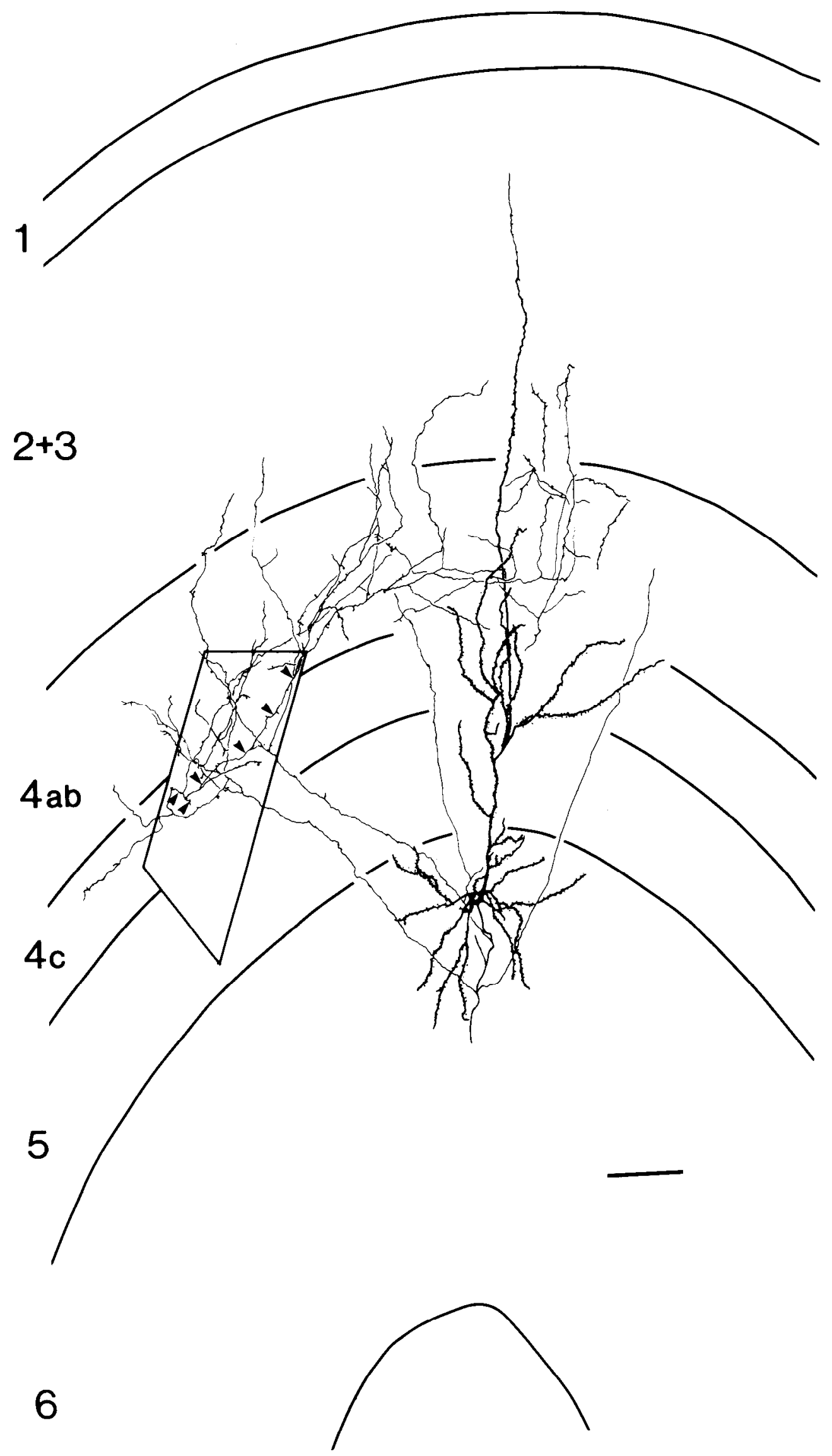

Figure 1. Camera lucida drawing of an HRP-labeled layer 6 pyramidal cell. A single section containing the labeled axon collaterals (arrowheads) was trimmed into a mesa (indicated by trapezoidal outline) for ultrathin serial sectioning. Scale bar $=100 \mu \mathrm{m}$. 


\section{1}

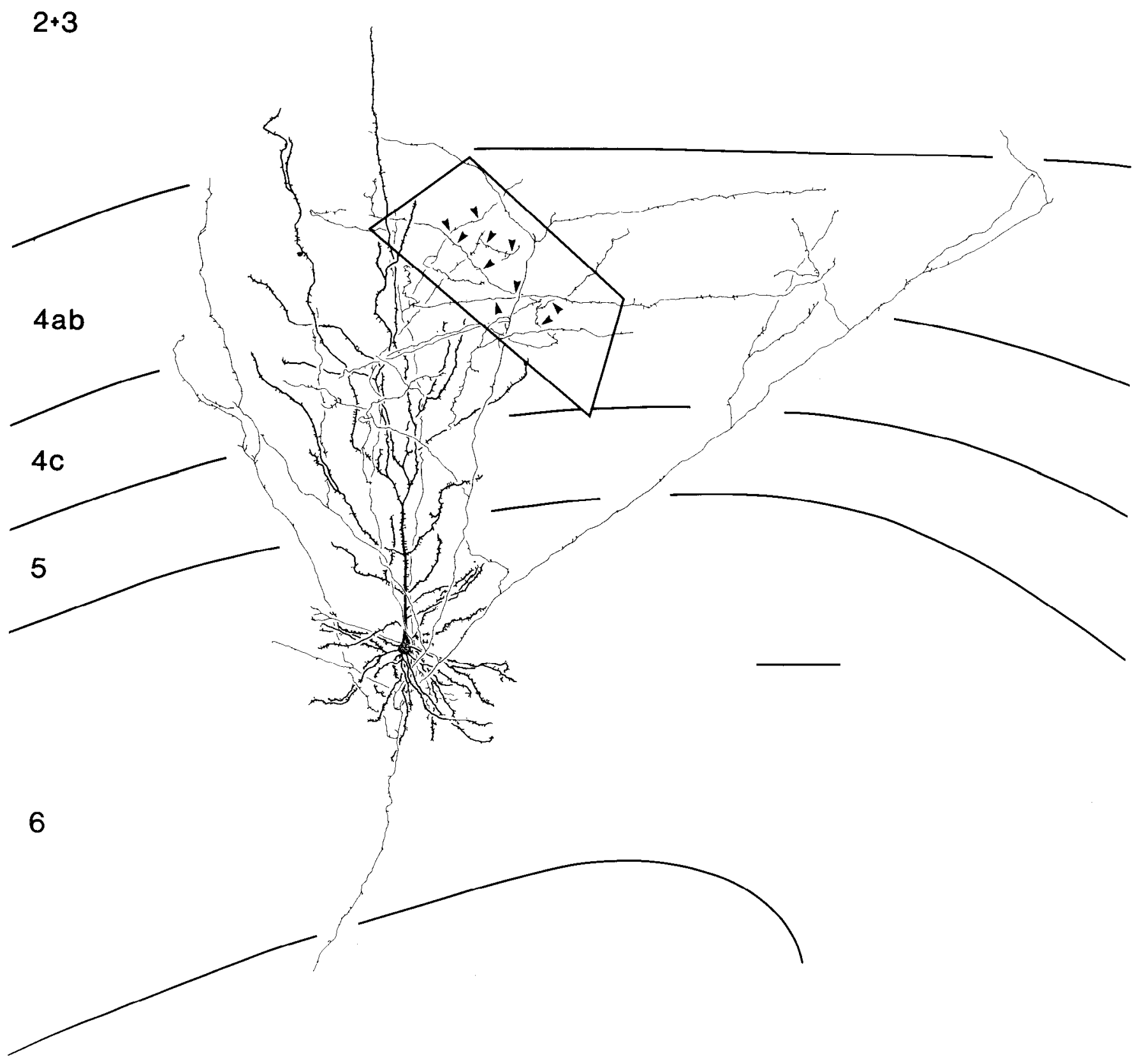

Figure 2. Camera lucida drawing of second HRP-labeled layer 6 pyramidal cell. Trapezoidal outline of mesa was trimmed for ultrathin serial sectioning indicated as in Figure 1. Scale bar $=100 \mu \mathrm{m}$.

The smooth dendrites represented a large proportion of the identified postsynaptic dendrites. Almost half $(40 \%)$ of the smooth dendrites were uniform in caliber (Fig. $6 a$ ), and the rest were beaded (Fig. 6, $b$ and $c$ ). Both types had a high density of synapses, most of which were asymmetric. The synaptic inputs to the beaded dendrites appeared not to distinguish between the varicosities and the interconnecting segments (Fig. 6). The cytoplasm in the constricted portions of the beaded dendrites appeared dense and filled with microtubules when compared to the pale, mitochondria-rich cytoplasm of the var- 

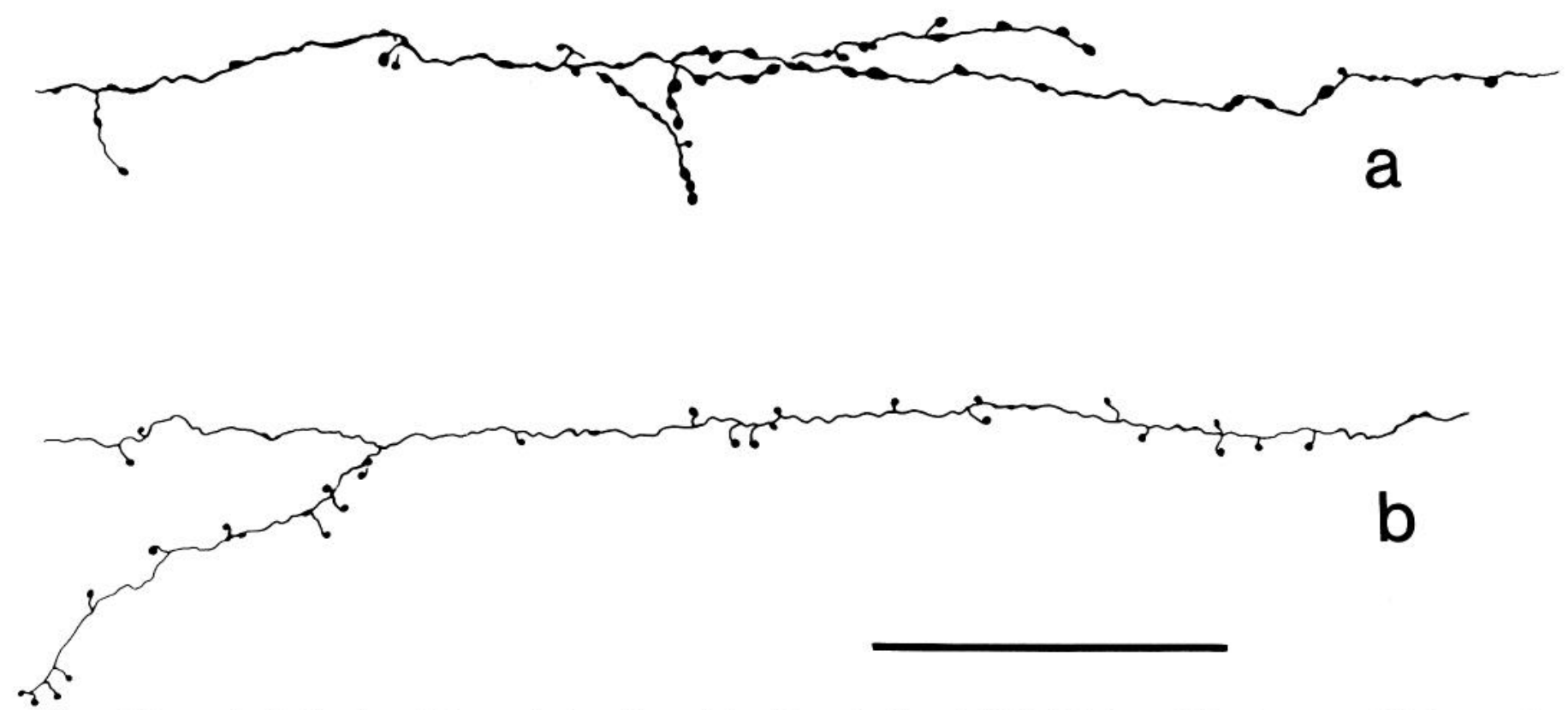

Figure 3. Camera lucida drawings of Y-on geniculate afferent $(a)$ and layer 6 collateral $(b)$, both in layer 4 . Note that most of the boutons for the LGN afferent are en passant, whereas most of the layer 6 boutons are on side twigs. The layer 6 axon collateral is also slender and delicate compared with the LGN afferent. Scale bar $=25 \mu \mathrm{m}$.
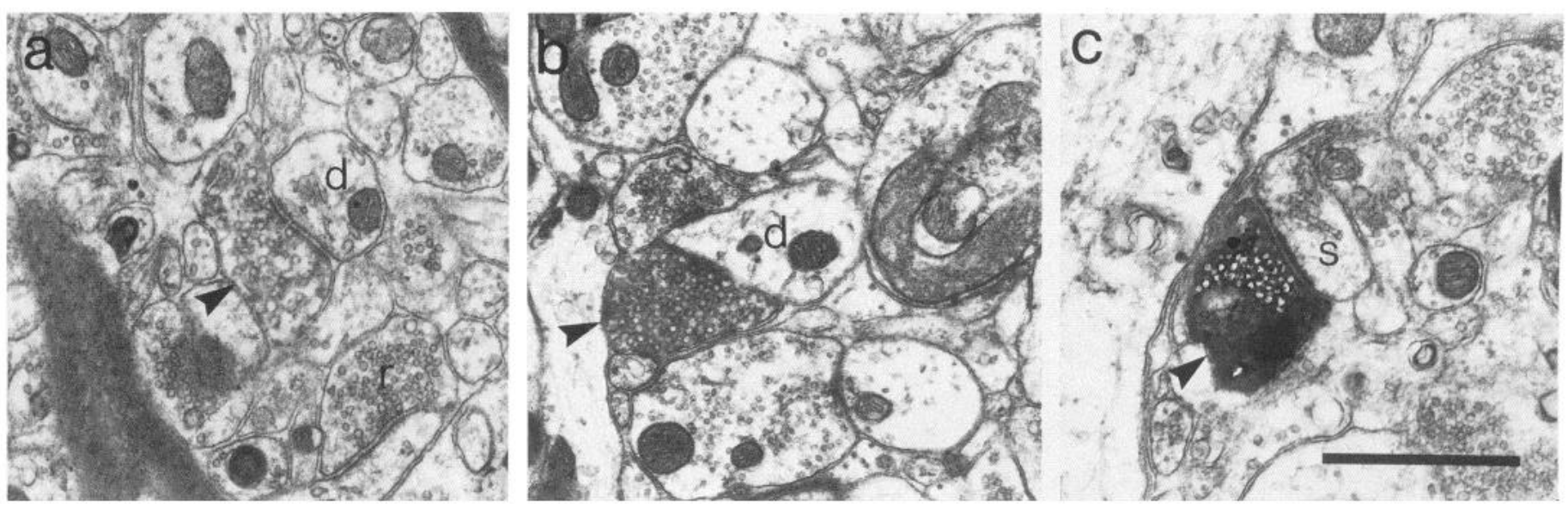

Figure 4. Electron micrographs of three HRP-labeled axon terminals (arrowheads). a, A very lightly labeled terminal, containing round vesicles, contacting the dendritic shaft $(d)$. The HRP reaction product is grayish and fuzzy, and is attached to synaptic vesicle membranes and the inner plasma membrane. Compare with the unlabeled round vesicle terminal $(r)$ nearby. Serial sections were helpful in locating such lightly labeled synapses. $b$, A moderately labeled terminal, contacting the dendritic shaft $(d)$ near an unlabeled asymmetric terminal. Most of the synapses were labeled to this degree. $c$, A very heavily labeled terminal, contacting the dendritic spine $(s)$ which contains spine apparatus. Here, the morphology of the vesicles is obscured by the dense reaction product. Note asymmetric thickening. Scale bar $=1 \mu \mathrm{m}$.

icosities (Fig. 7). For dendrites of uniform caliber, about half had dark cytoplasm like the constrictions of the beaded dendrites, and the other half had pale cytoplasm as seen in the varicosities of smooth dendrites and in the spiny (Fig. 8) and sparsely spiny dendrites.

At the other extreme, a small proportion of the dendrites could clearly be classified as spiny. In addition to their high spine density, they were also characterized by having sparse synaptic inputs on their dendritic shafts (Fig. $6, f$ and $g$ ). In one case (Fig. 6g), a postsynaptic spiny dendrite was oriented vertically, perpendicular to the pia, suggesting the possibility that layer 6 cells might also occasionally contact the apical dendrite of layer 5 or 6 pyramidal cells.

Intermediate between the smooth and spiny cells were the cells with few spines (fewer than 1 spine every $5 \mu \mathrm{m}$ ). The frequency of spines could be estimated with some confidence because the dendritic processes were examined over serial sec- tions at high power, between $\times 14,000$ and $\times 30,000$. This spine density is well within the range of that described for sparsely spiny neurons in visual cortex of the cat and rat (Peters and Feldman, 1977; Peters and Regidor, 1981). The sparsely spiny dendrites varied widely in the density of synapses on their shafts, but it was possible to divide them according to whether the synaptic density was high $(>1$ synapse/2 $\mu \mathrm{m}$, Fig. $6 d)$ or low ( $<1$ synapse $/ 2 \mu \mathrm{m}$, Fig. $6 e$ ). For comparison, spiny dendrites had low synaptic density and smooth dendrites had high synaptic density.

Of the 151 synaptic contacts made by the two layer 6 cells in layer 4, about half (77) could be reconstructed in sufficient detail to be classified as belonging to one of the groups described above. The remainder could not be classified, either because the postsynaptic spines could not be traced back to their parent dendrites (27 cases) or because the reconstructions of the postsynaptic dendrites were not sufficiently complete (47 


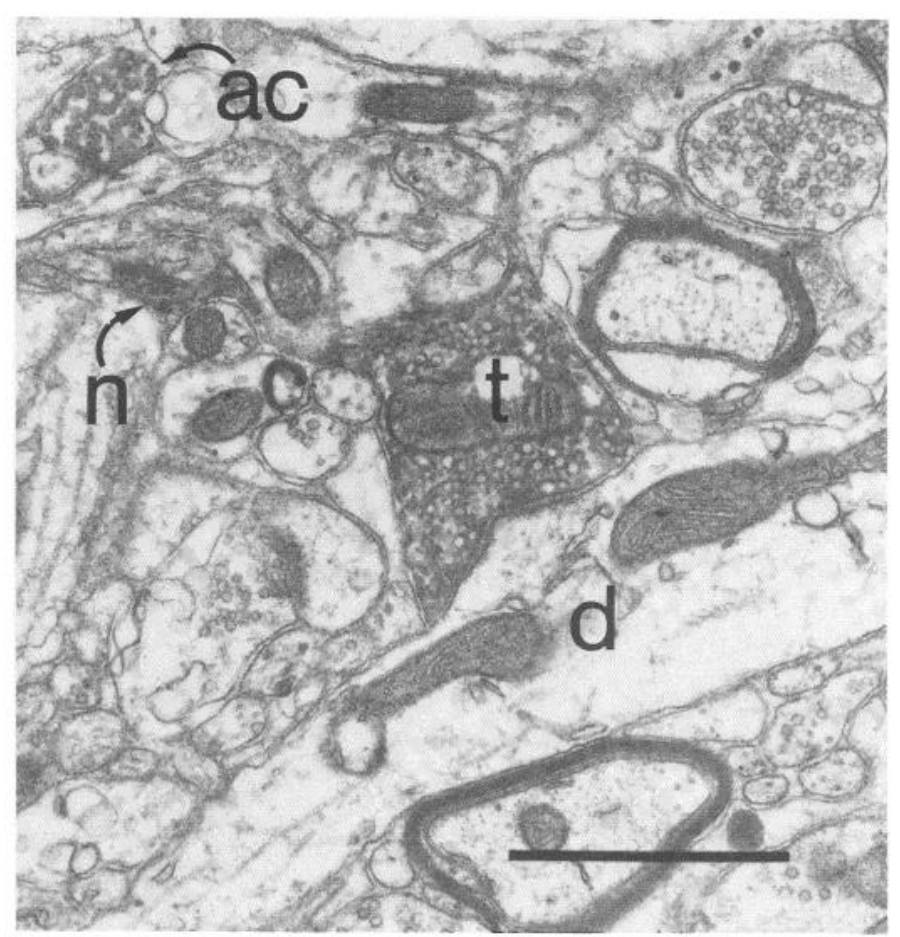

Figure 5. Electron micrograph showing labeled axon terminals from the neuron in Figure 1. Note the dense HRP reaction product within the synaptic terminal $(t)$ and main branch of the axon collateral $(a c)$. Note also the thin neck $(n)$ which connects the terminal to the parent axon in a different section. The terminal, containing many round vesicles, made an asymmetric synapse with a dendritic shaft $(d)$ which is reconstructed in Figure 6g. Scale bar $=1 \mu \mathrm{m}$.

TABLE I

Distribution of HRP-labeled layer 6 cell synapses onto postsynaptic sites within layer 4

\begin{tabular}{lccr}
\hline & Axodendritic & Axospinous & Total \\
\hline Identified & 66 & 11 & 77 \\
Unidentified & 42 & 32 & 74 \\
Total & $108(72 \%)$ & $43(28 \%)$ & 151 \\
\hline
\end{tabular}

cases). The relative proportions of each postsynaptic cell type are given in Table II. Since the distribution of postsynaptic dendrites was similar for the two neurons, we have combined the results from the two cells. The distribution was highly skewed in favor of the smooth and sparsely spiny cells, with the smooth cells representing $36 \%$ of the total identified cells, the sparsely spiny cells with high synaptic density $27 \%$, sparsely spiny cells with low synaptic density $30 \%$, and the spiny cells $7 \%$. As pointed out under "Discussion," these figures most likely underestimate the number of endings on spiny cells.

In only one instance was the labeled layer 6 input close enough to the cell body to make it possible to reconstruct the soma and proximal dendrites of a postsynaptic layer $4 \mathrm{c}$ neuron. The postsynaptic cell had a bipolar shape and emitted only one or two primary dendrites from either pole. It received a mixture of asymmetric and symmetric synapses on its soma (Fig. 9; see Feldman and Peters, 1978; Peters and Kimerer, 1981). In reconstructing its axon, we were able to characterize the synapses made by a cell that was postsynaptic to a layer 6 cell. Of 21 reconstructed synapses made by the bipolar neuron, 12 were made with spines or spine necks, and 9 were made with dendritic shafts. Both the vesicle morphology and postsynaptic thickening were intermediate between flat/symmetric and round/asymmetric (Fig. 9, b and $c$ ). Cells with similar morphology of somata and axon terminals have been described in the visual cortex of the rat and have been shown to have vasoactive intestinal polypeptide- or cholecystokinin-like immunoreactivity (Hendry et al., 1983b; Peters and Connor, 1983; Peters et al., 1983).

EM autoradiography. Because the results described above represented only a limited sample, we wished to use an independent technique to ascertain whether the pattern of innervation described above was representative of the entire population. We labeled layer 6 pyramidal cells and their collaterals in layer 4 autoradiographically by utilizing their property of selective high affinity uptake and retrograde transport of $\left[{ }^{3} \mathrm{H}\right]-\mathrm{D}$-aspartate, injected in the LGN (Baughman and Gilbert, 1981). This method is appropriate for specifically labeling the layer 6 corticogeniculate pathway, since such injections have been shown to heavily label layer 6 pyramidal cells, but not to label any relay neurons in the geniculate (Baughman and Gilbert, 1981). It can be assumed, therefore, that there is little, if any, anterograde transport of D-aspartate which would label LGN afferent synaptic terminals within layer 4 of striate cortex.

The light microscopic appearance of cortical autoradiograms was the same as that described by Baughman and Gilbert (1981). After 8 weeks exposure, there were labeled cell bodies in layer 6 and diffuse labeling in layer 4. Light autoradiography of semithin sections revealed that about $30 \%$ of the neurons in layer 6 were labeled in the region of cortex with the most radioactivity. In layer 4 and at the EM level, dendrites (presumably apical dendrites of the labeled layer 6 neurons) and axon terminals were labeled. Concentrating only on synaptic terminals, we found, using EM autoradiography of a short series of sections within layer 4 , that there was a preference for labeled synaptic terminals to contact dendritic shafts. Of a total of 107 labeled synaptic contacts (Fig. 10), 76 (71\%) contacted dendritic shafts, $24(22 \%)$ contacted spines, and $7(7 \%)$ contacted cell bodies. To determine whether the synapses containing silver grains were preferentially labeled compared to the general population of synapses, we counted every synaptic contact within the same region in a small volume of tissue. In this sample of 117 synapses (both symmetric and asymmetric), $56 \%$ were made with dendritic shafts, $40 \%$ with spines, $3 \%$ with cell somata, and $1 \%$ with axon initial segments. Although results such as these from EM autoradiography of tissue with low grain density can be imprecise, the aspartate-labeled terminals contacted a higher proportion of dendritic shafts when compared to the overall population of synapses, and the distribution of labeled synapses on shafts versus spines closely matched that of the two HRP-injected layer 6 cell collaterals.

\section{Discussion}

From studies on the connectivity of the cortex done at the light microscopic level, it is clear that the inputs to the cortex are restricted to particular layers, and that there is a systematic set of connections between layers. To develop a fuller picture of cortical microcircuitry and to understand the final role of each component of the cortical circuit, it is necessary to identify the specific cell types involved in individual connections. In the present study we have focused on the inputs to layer 4 from layer 6 and from the LGN by combining intracellular injection of HRP and serial EM reconstruction. Using this approach, the first rather striking finding was that these two inputs to layer 4 , although both presumably excitatory, were very distinct in their postsynaptic targets. Layer 6 cells preferentially contact dendritic shafts, whereas the geniculate afferents overwhelmingly contact dendritic spines. This can be seen either when examining the synaptology of single injected cells or when examining the behavior of the overall population autoradiographically. Even when a layer 6 cell contacts a spiny cell in layer 4 , it prefers to synapse with shafts rather than with spines (Fig. 6, Table II). 

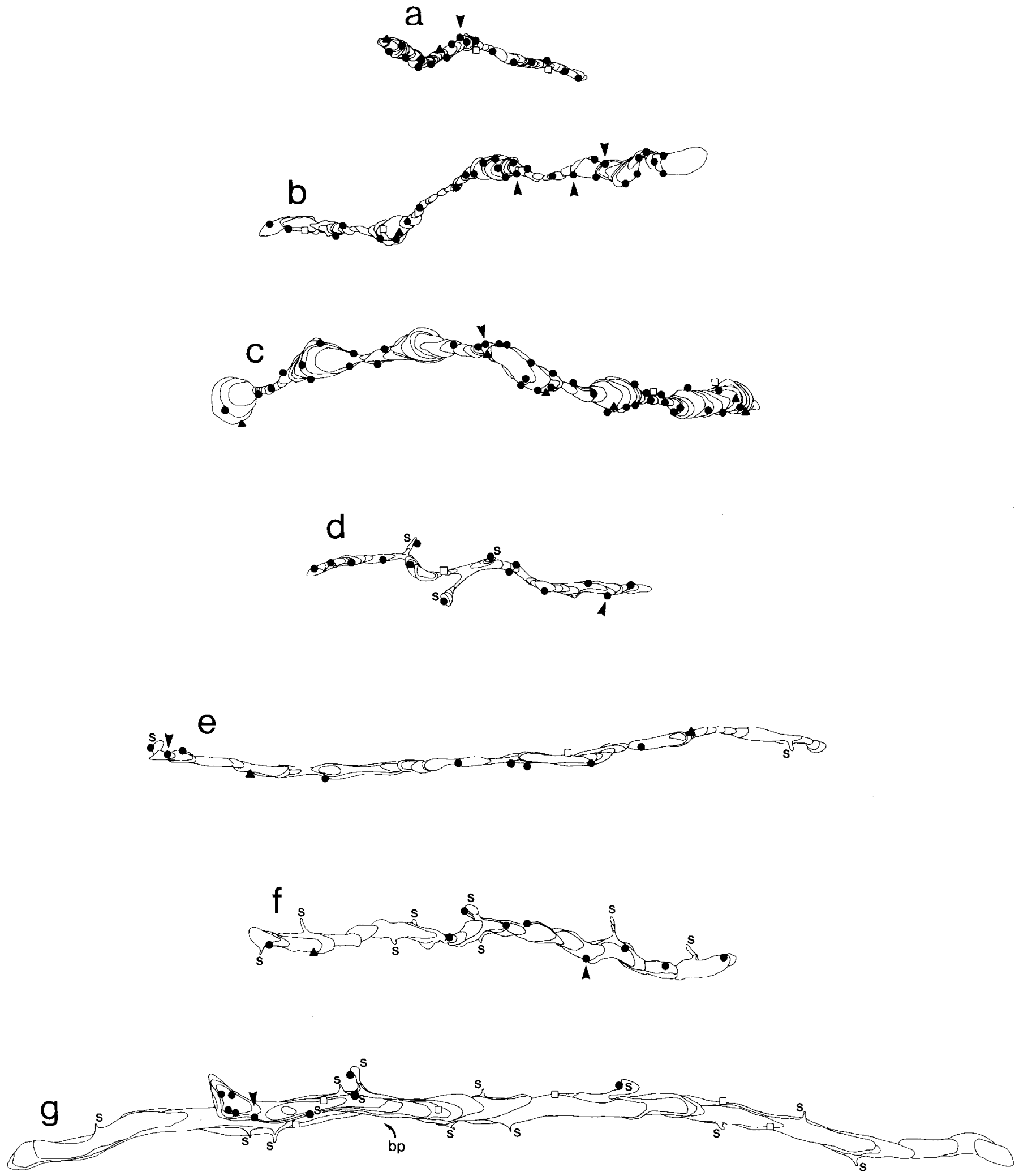

Figure 6. EM reconstructions of dendrites which were postsynaptic to the layer 6 cells. Synapses are indicated by solid circles (asymmetric), solid triangles (symmetric), or open squares (unclassified). Arrowheads indicate asymmetric synapses provided by the labeled layer 6 cells' axon terminals. Spine or spine neck is indicated by $s$. $a$, Smooth dendrite with uniform caliber. $b$ and $c$, Smooth, beaded dendrites. Note the high synaptic density of all three smooth dendrites and the predominantly asymmetric inputs. The dendrite in $b$ was the only dendritic segment in our sample of 77 identified dendrites which received more than a single labeled layer 6 input along the length reconstructed. Electron micrographs through a varicosity from dendrite $c$ are shown in Figure 7. $d$, Sparsely spiny dendrite with high synaptic density. $e$, Sparsely spiny dendrite with low synaptic density. $f$ and $g$, Spiny dendrites. From its orientation perpendicular to the pia, dendrite $g$ could be an apical dendrite belonging to a layer 5 or layer 6 pyramidal cell. To the left of the branch point $(b p)$, the two daughter branches and their synapses are superimposed. Scale $b a r=5 \mu \mathrm{m}$. 

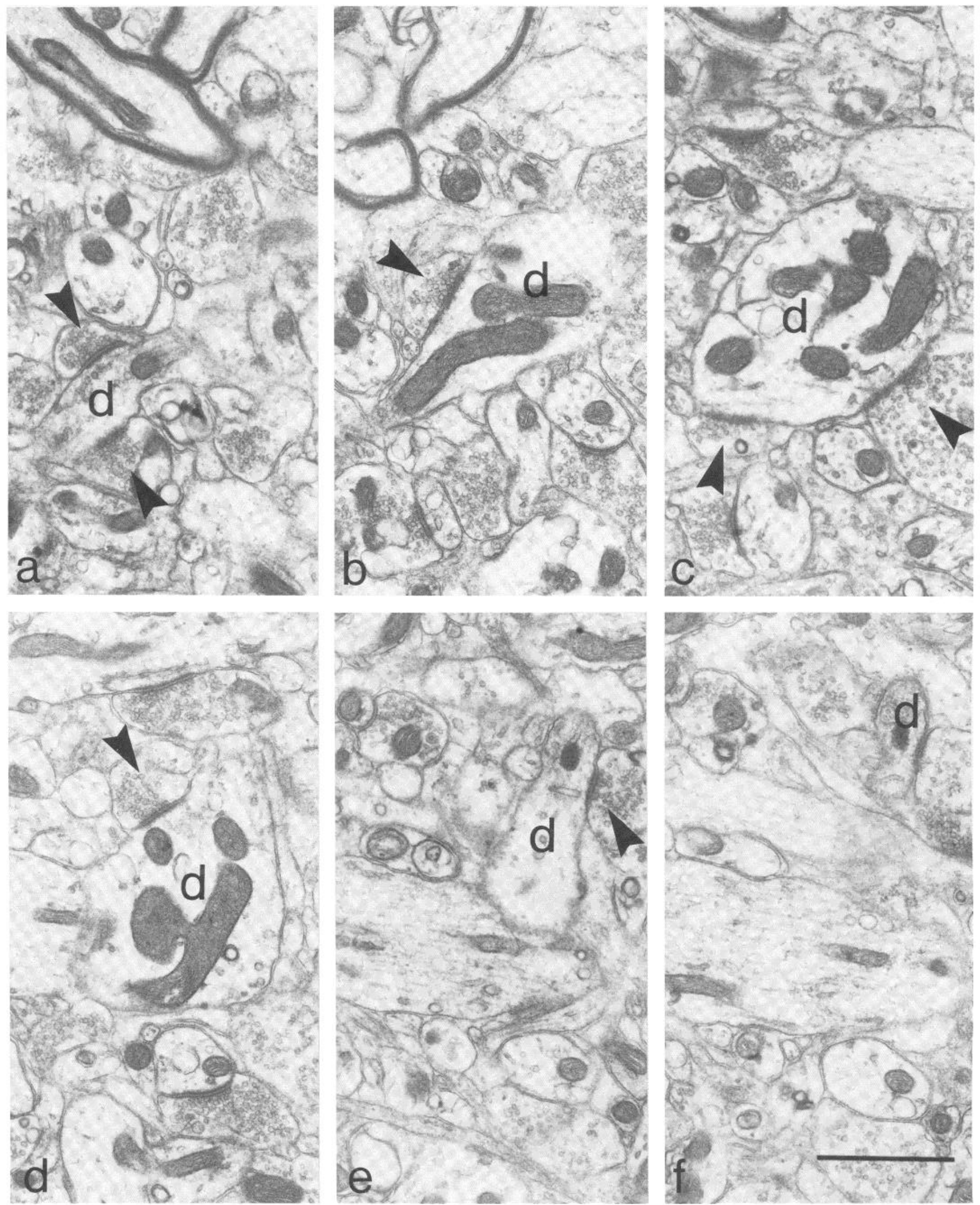

Figure 7. Semi-serial electron micrographs through a varicosity of a smooth, beaded dendrite (second varicosity from the left, Fig. $6 c$ ). Note the dark cytoplasm filled with microtubules in the constrictions ( $a$ and $e$ ) and pale cytoplasm filled with mitochondria in the varicosity ( $c$ and d). Synaptic inputs to this type of dendrite were very frequent, so that it was common (as above) to see on in almost every cross-section. Synaptic contacts were made both on the constricted portion $(a)$ and the varicosity $(c) . d$, postsynaptic dendrite. Arrowheads, asymmetric inputs. Scale bar $=1 \mu \mathrm{m}$. 

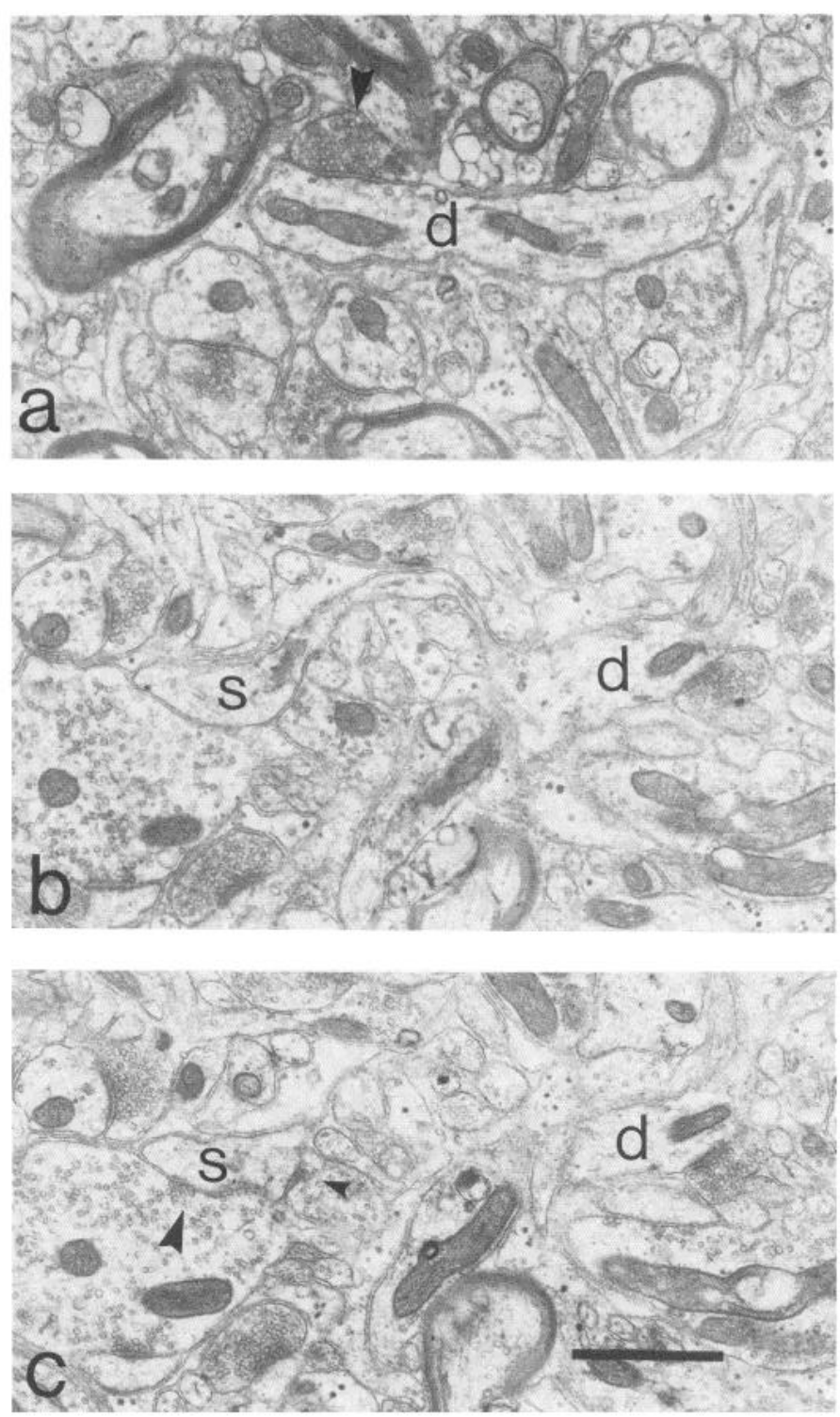

Figure 8. Electron micrograph of a spiny dendrite $(d)$ postsynaptic to the layer 6 cell. $a$, Dendrite with labeled layer 6 contact (arrowhead). $b$, Dendrite 25 sections later with spine $(s)$ attached via long, arching spine neck. Spine apparatus is visible in the spine head. $c$, Adjacent section, in which spine receives two synaptic inputs, one from a large, asymmetric terminal (large arrowhead), and a second, more proximal one, from a small, symmetric terminal (small arrowhead). Like the sparsely spiny dendrites, this spiny dendrite had pale cytoplasm with fewer organelles than the smooth, beaded dendrites. Scale bar $=1 \mu \mathrm{m}$.

TABLE II

Distribution of dendrite types identified by serial EM reconstruction which were contacted by HRP-labeled layer 6 cell axons

\begin{tabular}{lrrrr}
\hline & & & & \\
& Axodendritic & Axospinous & $\begin{array}{c}\text { Percentage of } \\
\text { Total } \\
\text { Identified }\end{array}$ \\
\hline Smooth & 28 & 0 & 28 & $36 \%$ \\
Sparsely spiny & 18 & 3 & 21 & $27 \%$ \\
$\quad$ High synaptic density & 16 & 7 & 23 & $30 \%$ \\
$\quad$ Low synaptic density & 4 & 1 & 5 & $7 \%$ \\
Spiny & 66 & 11 & 77 & $100 \%$ \\
Total identified & & & & \\
\hline
\end{tabular}

The next logical question is whether the difference in postsynaptic target is reflected in a preferential innervation of particular cell classes. To answer this we used the technique of serial EM reconstruction. Unfortunately, the technique is limited in that one cannot hope, in a reasonable period of time, to reconstruct fully all of the cells that are contacted by even a short axon collateral segment. However, to some degree it is possible to reconstruct a limited portion of postsynaptic dendrite and from that determine the general class of cell to which the dendrite belongs. In the present study we found that more than one-third of the layer 6 cell contacts were made with smooth dendrites. This figure is clearly distinct from the pattern of innervation by geniculate afferents. One can reasonably assume that the geniculate projection, in making at least $80 \%$ of its contacts with spines (Garey and Powell, 1971; LeVay and Gilbert, 1976; Winfield and Powell, 1983), contacts considerably fewer smooth stellate cells than does the layer 6 projection.

In considering the significance of our results it would be helpful to know the proportion of smooth, sparsely spiny, and spiny stellate cells in the overall population within layer 4 . At present we are limited by having insufficient information about the proportions of the various cell classes that exist in different layers. Various approaches, all of which are indirect, have been employed to estimate the proportions of smooth and sparsely spiny neurons. One criterion for identifying smooth stellate cells is based on their tendency to have mixed symmetric and asymmetric contacts on cell bodies (e.g., Colonnier, 1968; LeVay, 1973; see Colonnier, 1981). Estimating the proportion of smooth stellate cells in layer 4 by using this criterion gives numbers ranging from $5 \%$ in the primate (Lund, 1981) to $35 \%$ in the cat (Davis and Sterling, 1979). This method is complicated by the existence of spiny stellate cells having asymmetric axosomatic contacts (Parnavelas et al., 1977; Hornung and Garey, 1981). An alternative method is to determine the proportion of cells having GAD immunoreactivity, since GADpositive and GABA-labeled neurons are thought to be smooth and sparsely spiny (Ribak, 1978; Somogyi et al., 1981; Hendry et al., 1983a). This approach produces estimates of 8 to $15 \%$ (Fitzpatrick et al., 1983). Not all smooth and sparsely spiny neurons, however, are necessarily GABAergic. Thus, the above figures can only represent approximations for the proportion of these cell types. Although we believe that our results support the notion that there is a concentration of layer 6 input onto smooth and sparsely spiny stellate cells, we cannot be certain given the available figures.

Selective innervation of smooth or sparsely spiny dendrites by pyramidal cells has been suggested by others (Somogyi, 1978; Winfield et al., 1981). They based their classification of the postsynaptic cells on criteria such as the presence of asymmetric inputs or dense synaptic input on dendritic shafts seen in serial sections, although no serial reconstructions were done. These studies, taken together with our own, support the notion that some pyramidal cells may selectively innervate smooth stellate cells.

Since we have reconstructed only a limited portion of the postsynaptic dendrites, it is important to discuss the criteria used in establishing the relationship between our reconstructed dendrites and their respective cell classes. The strongest argument can be made in assigning the smooth dendrites to the class of smooth stellate cells, since only these cells lack spines and receive a very dense, primarily asymmetric synaptic input (LeVay, 1973; Peters and Fairen, 1978; Somogyi et al., 1983). Although we suspect that the cell bodies of these smooth stellate cells are located within layer 4 , it remains to be established whether any of them are located outside the layer. We can also be reasonably confident of the dendrites we have assigned to spiny neurons (either layer 4 spiny stellate cells or layer 5 or 6 pyramidal cells) because, in addition to having numerous 

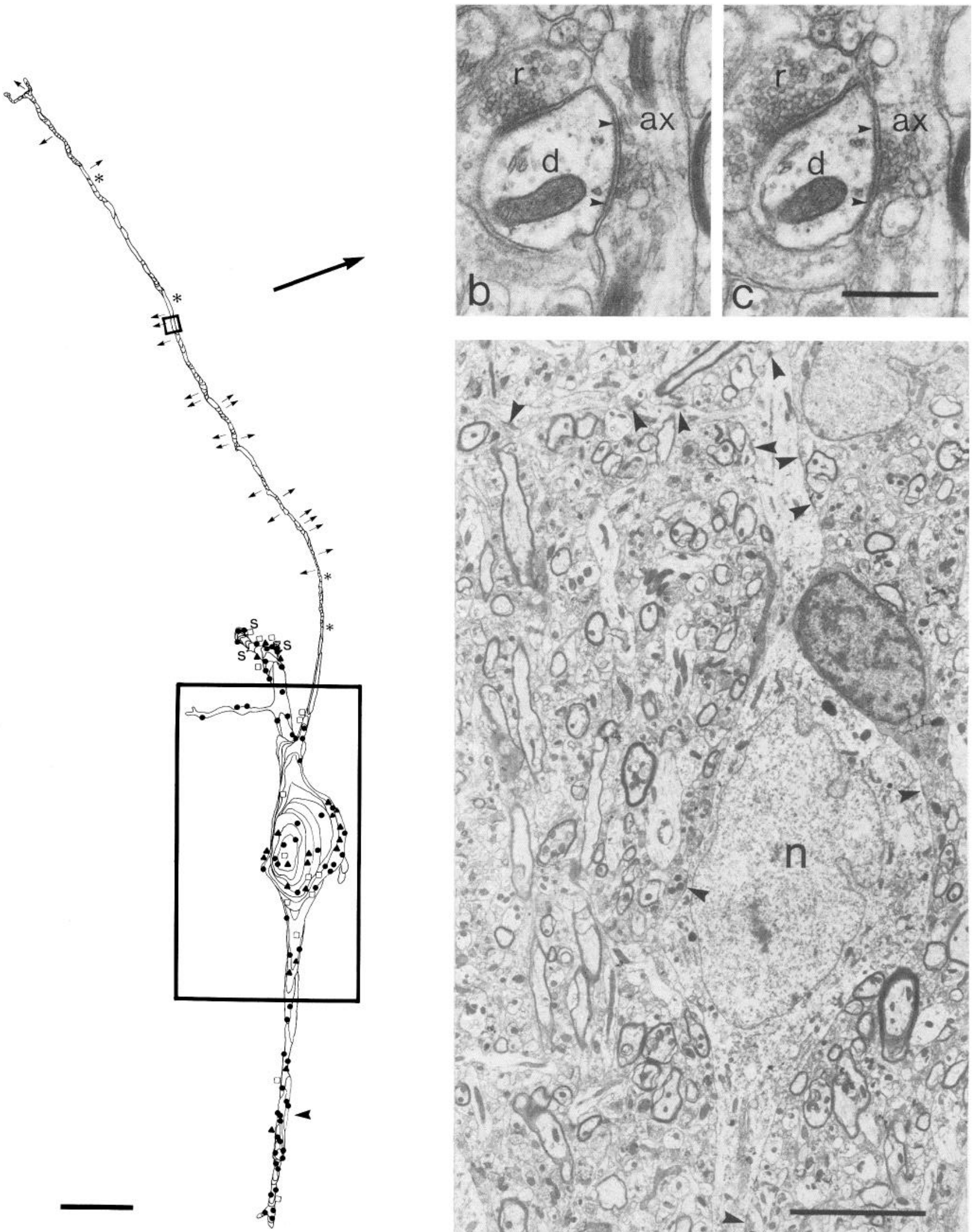

a

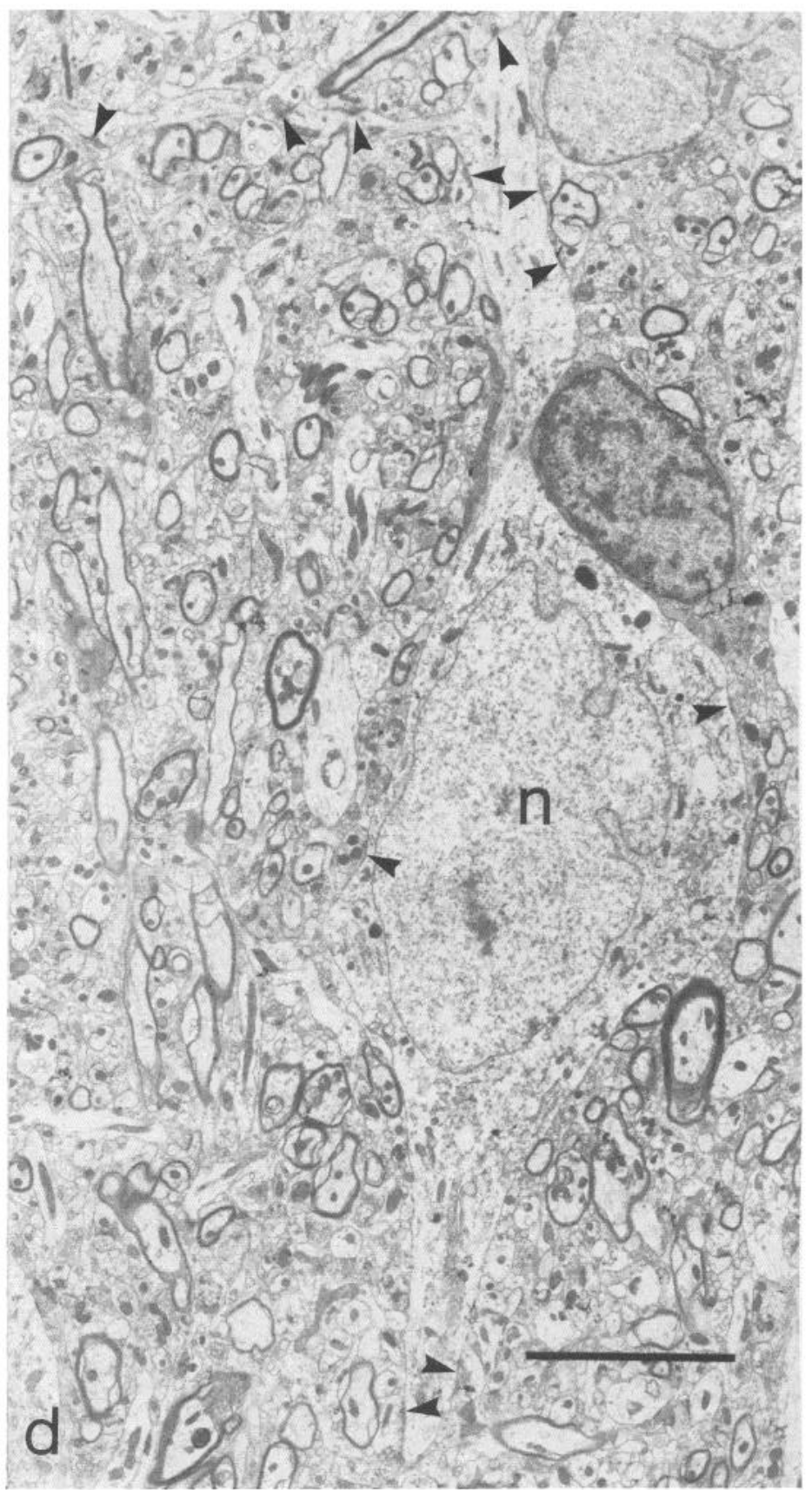



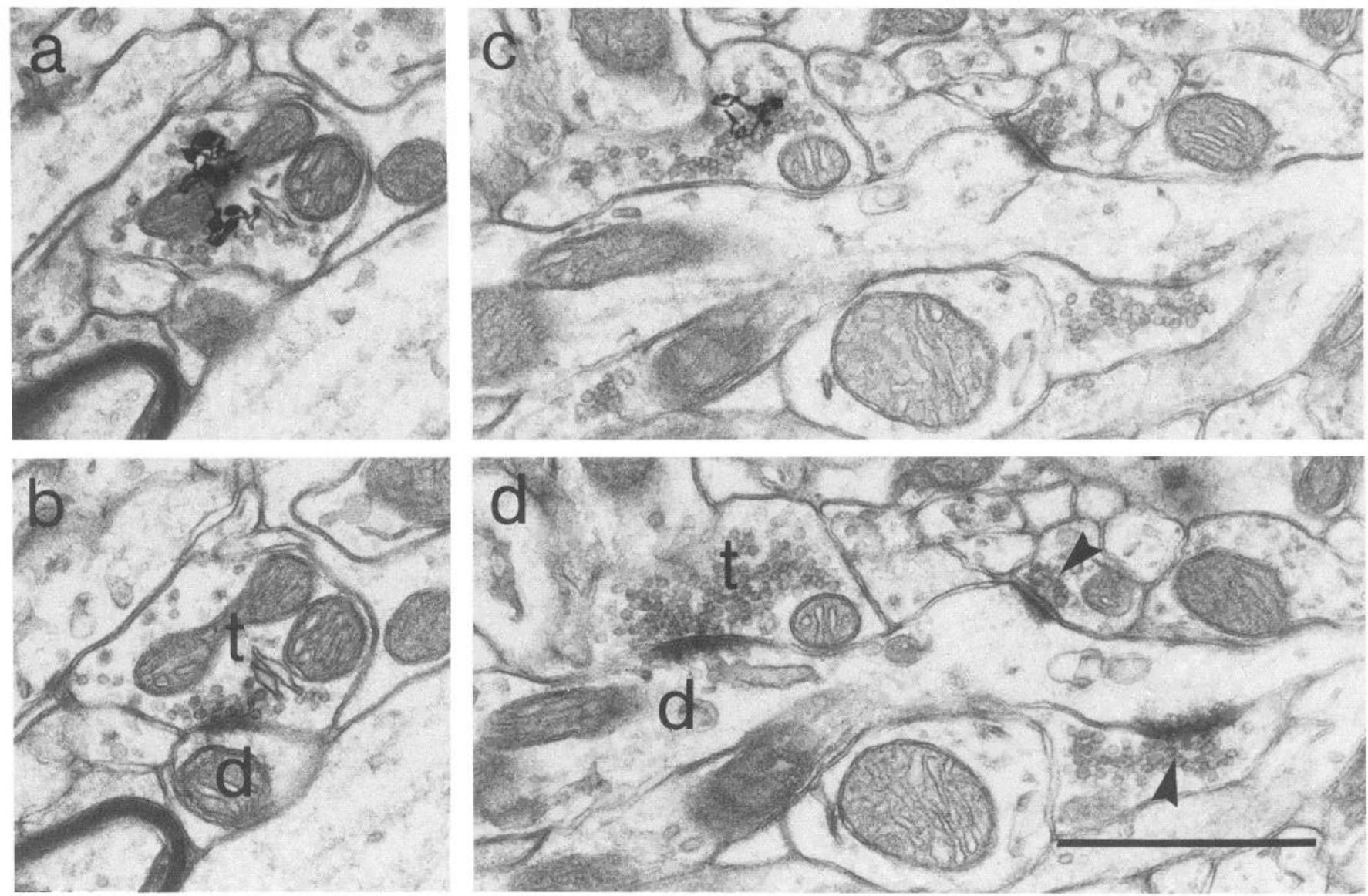

Figure 10. EM autoradiograms of two synaptic terminals labeled with $\left[{ }^{3} \mathrm{H}\right]-\mathrm{D}$-aspartate. $a$, Labeled synaptic terminal containing two silver grains. $b$, In an adjacent section, the synaptic terminal $(t)$ containing round vesicles contacts a dendritic shaft $(d)$. $c$, Labeled synaptic terminal (center), containing round vesicles. $d$, In the adjacent section, the synaptic terminal $(t)$ makes an asymmetric synapse with a dendritic shaft ( $d$ ), which receives two other asymmetric synapses (arrowheads) nearby, a configuration typical of smooth or sparsely spiny dendrites. Scale bar $=1$ $\mu \mathrm{m}$.

spines, the synaptic input to their dendritic shafts is quite sparse. However, there are several factors that can lead us to underestimate the proportion of these cells in the postsynaptic population. One is the fact that there were more labeled axospinous terminals among the unidentified than among the identified processes ( 32 versus 11 , Table I). A second source of error is the group of sparsely spiny dendrites with low synaptic density ( $30 \%$, Table II), many of which could belong to spiny neurons. If all of the dendrites in both of these groups belonged to spiny neurons, then the proportion of postsynaptic spiny cells would approach nearly $50 \%$. The neurons which we call sparsely spiny constitute more than half of the identified postsynaptic dendrites in this study. There is no consensus on the proportion or even the existence of these cells in the adult cat. We believe, however, that at least some of the postsynaptic dendrites, particularly those with high synaptic density, do belong to this class. Previous studies have characterized these cells as having few spines and a high density of synaptic inputs (primarily asymmetric) on their dendritic shafts. Furthermore, these cells have been shown to have axons which make symmetric synapses, consistent with a role in cortical inhibition (Colonnier, 1968; LeVay, 1973; Peters et al., 1976; Parnavelas et al., 1977; Peters and Fairen, 1978; Somogyi and Cowey, 1981).

Another important attribute of the layer 6 input was that it appeared to be located on the distal portions of the dendritic tree. None of the HRP-labeled axon terminals contacted cell somata, a distinction from the behavior of geniculate afferents which do occasionally make axosomatic contacts (Colonnier and Rossignol, 1969; Garey and Powell, 1971; LeVay, 1973; Davis and Sterling, 1979; Hornung and Garey, 1981). Furthermore, the cell body was found in only one instance out of 77 reconstructed postsynaptic dendrites. If layer 6 axonal contacts were common on the proximal dendrites of layer 4 cells, one

Figure 9. Bipolar cell postsynaptic to layer 6 neuron. $a$, EM serial reconstruction. Symbols are the same as in Figure 6 . The fully reconstructed soma emitted two major primary dendrites and a third, smaller dendrite which was not followed (lower right of soma). The soma received a mixture of asymmetric and symmetric synapses and bore a few spines on apical tertiary branches. The axon emerged from the apical dendrite and was myelinated in two short stretches, one near the initial segment (between small asterisks) and the second (between large asterisks) after making 18 synaptic outputs (arrows), one of which is shown nearby (see long arrow). Scale bar $=10 \mu \mathrm{m}$. $b$ and $c$, Electron micrographs of two adjacent sections, taken from the region shown in the small box in $a$. The axon of the bipolar cell (ax) made an intermediate type of synaptic contact (between arrowheads) onto a dendritic shaft $(d)$. Compare the bipolar cell's synaptic morphology with that of the asymmetric synapse ( $r$ ) containing round vesicles, above. See text for details. Scale bar $=1 \mu \mathrm{m}$. $d$, Electron micrograph of bipolar soma, as in the large box in $a$. The nucleus $(n)$ was infolded and eccentric. The cell body received only two synaptic inputs (arrowheads) in this single section, but serial reconstruction (see $a$ ) revealed that a total of 35 inputs were present. Scale bar $=5 \mu \mathrm{m}$. 
would expect to recover a higher percentage of cell bodies, since the average length of the identified reconstructed dendrites was about $15 \mu \mathrm{m}$. Finally, many of the postsynaptic dendrites were quite slender (see Fig. 6, $a, d$, and $e$ ). This preference for distal dendrites has also been observed for layer 6 terminals in the LGN (Guillery, 1969; Robson, 1983).

From the above findings concerning the pattern of innervation of layer 4 by layer 6 cells and from previous studies on the physiological properties of cells in these two layers, it is possible to speculate on the functional role of this pathway. First, it is likely that the layer 6 cells are excitatory, since they make asymmetric synapses with round vesicles, a feature associated with excitation in other regions (Uchizono, 1965; see Colonnier, 1981), and since they show high affinity uptake of the excitatory acidic amino acid transmitters (Baughman and Gilbert, 1981). Although the layer 6 pyramidal cells may themselves be excitatory, they can still exert a powerful inhibitory influence by their frequent contacts with smooth stellate cells. Smooth stellate cells are thought to be inhibitory since they form symmetric synapses (LeVay, 1973; Parnavelas et al., 1977; Peters and Fairen, 1978; Fairen and Valverde, 1980; Somogyi and Cowey, 1981; DeFelipe and Fairen, 1982; Somogyi et al., 1983), preferentially take up the inhibitory transmitter GABA (Chronwall and Wolff, 1978; Somogyi et al., 1981, 1983; Hamos et al., 1983), and are labeled with antibodies to the GABA synthetic enzyme, GAD (Ribak, 1978; Hendry et al., 1983a; Somogyi et al., 1983).

There are a number of receptive field features that may depend on inhibition. By applying an antagonist to the inhibitory transmitter GABA, Sillito and co-workers (Sillito, 1977; Sillito and Versiani, 1977; Sillito et al., 1980) have found that directional specificity, orientation, and end-inhibition can be reduced or eliminated. Since many layer 6 neurons which project to layer 4 have long receptive fields, this pathway may be useful for generating orientation selectivity, either by excitatory or inhibitory mechanisms. For many cortical neurons the precision of orientation sensitivity increases if the stimulus length is increased. This property could be produced by layer 6 cells projecting, via an inhibitory interneuron, to layer 4 cells with different orientation specificities. Another possible role for the pathway is end-inhibition, since the end-inhibitory regions of layer 4 cells appear to be comparable in extent to the long receptive fields of layer 6 cells (Gilbert, 1977). Support for the idea that end-inhibition is produced by cells with long receptive fields comes from the findings of Sherk and LeVay (1981, 1983). They showed that cells in the claustrum have receptive fields that are very similar to many layer 6 cells, and that lesions in the claustrum cause a reduction in the amount of end-inhibition in the cortex. However, after claustral lesions, there is still substantial residual end-inhibition among layer 4 cells (Sherk and LeVay, 1983). This remaining end-inhibition may be mediated by the layer 6 cells with long receptive fields. One problem with this model, however, is that one would expect to find cells in layer 4 with long receptive fields. Although this has not yet been reported, the relative scarcity of inhibitory interneurons and the difficulty of determining receptive field length without the appropriate quantitative methods leaves open the possibility that such cells do exist in layer 4 .

In addition to their possible inhibitory role within layer 4 , the layer 6 cells, by their contacts with spiny cells, may also participate in excitatory processes that are carried through to other layers. This could explain the results of Ferster and Lindstrom (1983), who, after lesioning the LGN with kainic acid, found that antidromic activation of layer 6 cells leads to some excitation in all cortical layers.

This study represents an initial step in trying to elaborate the functional consequences of cortical connectivity. One can anticipate that as further information becomes available on the distribution of different synaptic and cell types in the cortex, as one develops more concrete ways of identifying individual cell classes at the ultrastructural level, and as one can more reliably use morphological cues to predict whether a cell is excitatory or inhibitory, it will then be possible to relate the cortical circuit to cortical function more definitively.

\section{References}

Adams, J. C. (1977) Technical considerations on the use of horseradish peroxidase as a neuronal marker. Neuroscience 2: 141 .

Baughman, R. W., and C. D. Gilbert (1981) Aspartate and glutamate as possible neurotransmitters in the visual cortex. J. Neurosci. I: $427-439$.

Chronwall, B. M., and J. R. Wolff (1978) Classification and location of neurons taking up ${ }^{3} \mathrm{H}$-GABA in the visual cortex. In Amino Acids us Chemical Transmitters, F. Fonnum, ed., pp. 297-303, Plenum Press, New York.

Colonnier, M. (1968) Synaptic patterns on different cell types in the different laminae of the cat visual cortex. An electron microscope study. Brain Res. 9: 268-287.

Colonnier, M. (1981) The electron-microscopic analysis of the neuronal organization of the cerebral cortex. In The Organization of the Cerebral Cortex, F. O. Schmitt, F. G. Worden, G. Adelman, and S. G. Dennis, eds., pp. 125-152, MIT Press, Cambridge, MA.

Colonnier, M., and S. Rossignol (1969) Heterogeneity of the cerebral cortex. In Basic Mechanisms of the Epilepsies, H.H. Jasper, A.A. Ward, Jr., and A. Pope, eds., pp. 29-40, Little, Brown and Co., Boston.

Davis, T. L., and P. Sterling (1979) Microcircuitry of cat visual cortex: Classification of neurons in layer IV of area 17, and identification of the patterns of lateral geniculate input. J. Comp. Neurol. 188: 599 628.

Davis, T. L., R. F. Spencer, and P. Sterling (1979) Preparing autoradiograms of serial sections for electron microscopy. J. Neurosci. Methods 1: 179-183.

DeFelipe, J., and A. Fairen (1982) A type of basket cell in superficial layers of the cat visual cortex. A Golgi-electron microscope study. Brain Res. 244: 9-16.

Fairen, A., and F. Valverde (1980) A specialized type of neuron in the visual cortex of cat. A Golgi and electron microscope study of chandelier cells. J. Comp. Neurol. 194: 761-794.

Feldman, M. L., and A. Peters (1978) The forms of non-pyramidal neurons in the visual cortex of the rat. J. Comp. Neurol. 179: 761794.

Ferster, D., and S. Lindstrom (1983) Synaptic effects mediated by intracortical axon collaterals of cortico-geniculate neurones in area 17 of the cat. J. Physiol. (Lond.) 341: 79P.

Fitzpatrick, D., J. S. Lund, and D. Schmechel (1983) Glutamic acid decarboxylase immunoreactive neurons and terminals in the visual cortex of monkey and cat. Soc. Neurosci. Abstr. 9: 616.

Garey, L. J., and T. P. S. Powell (1971) An experimental study of the termination of the lateral geniculo-cortical pathway in the cat and monkey. Proc. R. Soc. Lond. (Biol.) 179: 41-63.

Gilbert, C. D. (1977) Laminar differences in receptive field properties in cat primary visual cortex. J. Physiol. (Lond.) 268: 391-421.

Gilbert, C. D., and T. N. Wiesel (1979) Morphology and intracortical projections of functionally characterised neurones in the cat visual cortex. Nature 280: 120-125.

Gilbert, C. D., and T. N. Wiesel (1981) Laminar specialization and intracortical connections in cat primary visual cortex. In The Organization of the Cerebral Cortex, F.O. Schmitt, F.G. Worden, G. Adelman, and S.G. Dennis, eds., pp. 163-194, MIT Press, Cambridge, MA.

Gilbert, C. D., and T. N. Wiesel (1983) Clustered intrinsic connections in cat visual cortex. J. Neurosci. 3: 1116-1133.

Guillery, R. W. (1969) The organization of synaptic interconnections in the laminae of the dorsal lateral geniculate nucleus of the cat. $Z$. Zellforsch. 96: 1-38.

Hamos, J. E., T. L. Davis, and P. Sterling (1983) Four types of neuron in layer IVab of cat cortical area 17 accumulate ${ }^{3} \mathrm{H}-\mathrm{GABA}$. J. Comp. Neurol. 217: 449-457.

Hendry, S. H. C., C. H. R. Houser, E. G. Jones, and J. E. Vaughn (1983a) Synaptic organization of immunocytochemically identified GABA neurons in the monkey sensory-motor cortex. J. Neurocytol. 12: 639-660. 
Hendry, S. H. C., E. G. Jones, and M. C. Beinfeld (1983b) Cholecystokinin-immunoreactive neurons in rat and monkey cerebral cortex make symmetric synapses and have intimate associations with blood vessels. Proc. Natl. Acad. Sci. U. S. A. 80: $2400-2404$

Hornung, J. P., and L. J. Garey (1981) The thalamic projection to cat visual cortex: Ultrastructure of neurons identified by Golgi impregnation or retrograde horseradish peroxidase transport. Neuroscience 6: $1053-1068$.

Hubel, D. H., and T. N. Wiesel (1962) Receptive fields, binocular interaction and functional architecture in the cat's visual cortex. J. Physiol. (Lond.) 160: 106-154.

LeVay, S. (1973) Synaptic patterns in the visual cortex of the cat and monkey. Electron microscopy of Golgi preparations. J. Comp. Neurol. 150: 53-86.

I.eVay, S., and C. D. Gilbert (1976) Taminar patterns of geniculocortical projection in the cat. Brain Res. 113: 1-19.

Lund, J. S. (1981) Intrinsic organization of the primate visual cortex, Area 17, as seen in Golgi preparations. In The Organization of the Cerebral Cortex, F.O. Schmitt, F. G. Worden, G. Adelman, and S.G. Dennis, eds., pp. 105-124, MIT Press, Cambridge, MA.

Lund, J. S., and R. G. Boothe (1975) Interlaminar connections and pyramidal neuron organisation in the visual cortex, area 17 , of the macaque monkey. J. Comp. Neurol. 159: 305-334.

Lund, J. S., G. H. Henry, C. L. Macqueen, and A. R. Harvey (1979) Anatomical organization of the primary visual cortex (area 17) of the cat. A comparison with area 17 of the macaque monkey. J. Comp. Neurol. 184: 599-618.

Parnavelas, J. G., K. Sullivan, A. R. Lieberman, and K. E. Webster (1977) Neurons and their synaptic organization in the visual cortex of the rat. Electron microscopy of Golgi preparations. Cell Tissue Res. 183: 499-517.

Peters, A., and J. Connor (1983) VIP-positive cells in the rat visual cortex. Soc. Neurosci. Abstr. 9: 1181.

Peters, A., and A. Fairen (1978) Smooth and sparsely-spined stellate cells in the visual cortex of the rat: A study using a combined Golgielectron microscope technique. J. Comp. Neurol. 181: 129-172.

Peters, A., and M. L. Feldman (1977) The projection of the lateral geniculate nucleus to area 17 of the rat cerebral cortex. IV. Terminations upon spiny dendrites. J. Neurocytol. 6: 669-689.

Peters, A., and L. M. Kimmerer (1981) Bipolar neurons in rat visual cortex: A combined Golgi-electron microscope study. J. Neurocytol. 10: 921-946.

Peters, A., and J. Regidor (1981) A reassessment of the forms of nonpyramidal neurons in area 17 of cat visual cortex. J. Comp. Neurol. 203: 685-716.

Peters, A., M. Feldman, and J. Saldanha (1976) The projection of the lateral geniculate nucleus to area 17 of the rat cerebral cortex. II. Terminations upon neuronal perikarya and dendritic shafts. J. Neurocytol. 5: 85-107.

Peters, A., M. Miller, and L. M. Kimmerer (1983) Cholecystokinin-like immunoreactive neurons in rat cerebral cortex Neuroscience 8: 431448.

Ribak, C. E. (1978) Aspinous and sparsely-spinous stellate neurons in visual cortex of rats contain glutamic acid decarboxylase. J. Neurocytol. 7: 461-478.

Robson, J. A. (1983) The morphology of corticofugal axons to the dorsal lateral geniculate nucleus in the cat. J. Comp. Neurol. 216 : 89-103.

Sherk, H., and S. LeVay (1981) The visual claustrum of the cat. III. Receptive field properties. J. Neurosci. 1: 993-1002.

Sherk, H., and S. LeVay (1983) Contribution of the cortico-claustral loop to receptive field properties in area 17 of the cat. J. Neurosci. 3: 2121-2127.

Sillito, A. M. (1977) Inhibitory processes underlying the directional specificity of simple, complex and hypercomplex cells in the cat's visual cortex. J. Physiol. (Lond.) 271: 699-720.

Sillito, A. M., and A. Versiani (1977) The contribution of excitatory and inhibitory inputs to the length preference of hypercomplex cells in layer II and III of the cat's striate cortex. J. Physiol. (Lond.) 273: $775-790$.

Sillito, A. M., J. A. Kemp, J. A. Milson, and N. Berardi (1980) A reevaluation of the mechanisms underlying simple cell orientation selectivity. Brain Res. 194: 517-520.

Somogyi, P. (1978) The study of Golgi stained cells and of experimental degeneration under the electron microscope: A direct method for the identification in the visual cortex of three successive links in a neuron chain. Neuroscience 3: 167-180.

Somogyi, P., and A. Cowey (1981) Combined Golgi and electron microscopic study on the synapses formed by double bouquet cells in the visual cortex of the cat and monkey. J. Comp. Neurol. 195: 547-566.

Somogyi, P., T. F. Freund, N. Halasz, and Z. F. Kisvarday (1981) Selectivity of neuronal $\left[{ }^{3} \mathrm{H}\right] \mathrm{GABA}$ accumulation in the visual cortex as revealed by Golgi staining of the labeled neurons. Brain Res. 225: 431-436.

Somogyi, P., Z. F. Kisvarday, K. A. C. Martin, and D. Whitteridge (1983) Synaptic connections of morphologically identified and physiologically characterized large basket cells in the striate cortex of the cat. Neuroscience 10: 261-294.

Stevens, J. K., T. L. Davis, N. Friedman, and P. Sterling (1980) A systematic approach to reconstructing microcircuitry by electron microscopy of serial sections. Brain Res. Rev. 2: 265-293.

Streit, P. (1980) Selective retrograde labeling indicating the transmitter of neuronal pathways. J. Comp. Neurol. 191: 429-463.

Uchizono, K. (1965) Characteristics of excitatory and inhibitory synapses in the central nervous system of the cat. Nature 207: 642-643.

Winfield, D. A., and T. P. S. Powell (1983) Laminar cell counts and geniculo-cortical boutons in area 17 of cat and monkey. Brain Res. 277: 223-229.

Winfield, D. A., R. N. L. Brooke, J. J. Sloper, and T. P. S. Powell (1981) A combined Golgi-electron microscopic study of the synapses made by the proximal axon and recurrent collaterals of a pyramidal cell in the somatic sensory cortex of the monkey. Neuroscience 6 : $1217-1230$. 